\title{
High Temperature Oxidation of Spark Plasma Sintered and Thermally Sprayed FeAl-Based Iron Aluminides
}

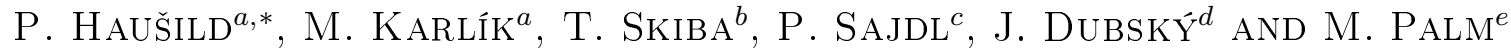 \\ ${ }^{a}$ Czech Technical University in Prague, Faculty of Nuclear Sciences and Physical Engineering \\ Department of Materials, Trojanova 13, 12000 Prague 2, Czech Republic \\ ${ }^{b}$ Research Centre Rez Ltd., Husinec-Rez 130, 25068 Rez, Czech Republic \\ ${ }^{c}$ Institute of Chemical Technology Prague, Technická 5, 16628 Prague 6, Czech Republic \\ ${ }^{d}$ Institute of Plasma Physics AS CR, v. v. i., Department of Materials Engineering \\ Za Slovankou 3, 18200 Prague 8, Czech Republic \\ ${ }^{e}$ Max-Planck-Institut für Eisenforschung GmbH, Max-Planck-Str. 1, D-40237 Düsseldorf, Germany
}

\begin{abstract}
The presented work deals with the oxidation resistance of spark plasma sintered and thermally sprayed FeAl-based intermetallics. Gas-atomized binary single phase $\mathrm{Fe}-43$ (at.\%)Al and dual phase $\mathrm{Fe}-55($ at.\%)Al powders were used for spark plasma sintering and/or thermal spraying. Coatings were deposited by two different plasma spray technologies — gas and water stabilized plasma guns. The prepared samples were exposed to oxidation in artificial air at $700{ }^{\circ} \mathrm{C}$. The mass gain was measured during oxidation at $700{ }^{\circ} \mathrm{C}$ up to $1000 \mathrm{~h}$. Microstructures, phase and chemical compositions of the formed scales were characterized after the exposition by means of scanning electron microscopy, X-ray diffraction and electron spectroscopy for chemical analysis (X-ray photoelectron spectroscopy).
\end{abstract}

PACS: 81.05.Bx, 81.65.Mq, 81.20.Ev, 81.15.Rs

\section{Introduction}

The excellent high temperature oxidation resistance of Al-rich iron aluminides is due to the formation of alumina scales [1-3], which form readily above approximately $500{ }^{\circ} \mathrm{C}[4]$. The best oxidation protection is obtained by $\alpha-\mathrm{Al}_{2} \mathrm{O}_{3}$, which is stable in binary $\mathrm{Fe}-\mathrm{Al}$ above $900^{\circ} \mathrm{C}$ $[5,6]$. At lower temperatures, less effective but still protective $\mathrm{Al}_{2} \mathrm{O}_{3}$ polytypes form, e.g. $\theta$ - or $\gamma-\mathrm{Al}_{2} \mathrm{O}_{3}[7]$.

The major weakness of FeAl based intermetalic alloys is their brittleness at room temperature [8-11]. Because of the difficulties in conventional metallurgical processing of iron aluminides with $\mathrm{Al}$ contents higher than 40 at.\% research efforts have focused on powder metallurgy [12-16] or thermal spray techniques [17-23]. Among the powder metallurgical techniques, spark plasma sintering (SPS) offers very fast densification which is important to maintain the initial grain (powder) size in the sintered material.

Among the thermal spray techniques, high velocity oxy-fuel (HVOF) spraying is the most used to produce thick coatings from FeAl powders. However, gas stabilized plasma (GSP) or water stabilized plasma (WSP)

\footnotetext{
* corresponding author; e-mail: Petr.Hausild@fjfi.cvut.cz
}

torches can provide much higher feed-rates than HVOF and are therefore more suitable for depositing protective layers on larger surfaces.

Although there has been an extensive research on high temperature oxidation behaviour of $\mathrm{FeAl}$ iron aluminides, the majority of published papers deals with bulk samples and/or is limited to temperatures above $800^{\circ} \mathrm{C}$. The purpose of present work is to characterize the oxidation behaviour at $700^{\circ} \mathrm{C}$ of SPS and plasma sprayed binary FeAl alloys.

\section{Experimental details}

The feedstock materials were atomized powders with compositions of $\mathrm{Fe}-43 \mathrm{at} . \% \mathrm{Al}$ and $\mathrm{Fe}-56 \mathrm{at} . \% \mathrm{Al}$. The powders were denoted SP (single phase) and DP (dual phase), as they contain B2 FeAl only and FeAl plus decomposed $\varepsilon$ eutectoid $\left(\mathrm{FeAl}+\mathrm{FeAl}_{2}\right)$, respectively. The powders were sieved into size fractions $<32,50-90$ and 90-140 $\mu \mathrm{m}$, which were used for SPS, GSP and WSP, respectively. The spark plasma sintering of compact specimens was carried out in a FCT HP D 25/1 FAST device. $\mathrm{FeAl}$ powders were also deposited on low carbon steel substrates by two plasma spraying technologies: gas stabilized plasma torch SulzerMetco F4 and water stabilized plasma torch PAL 160. Due to the lower quantity of the 
feedstock powder, the DP coatings were obtained only by GSP torch. Further processing details as well as the mechanical properties of FeAl SPS compacts and plasma sprayed coatings can be found in Refs. [24, 25].

SPS compacts and plasma sprayed coatings (removed from the substrate) were cut by a diamond saw into rectangular samples and used for thermogravimetric oxidation tests in a Setaram SETSYS 16/18 thermobalance. Samples were oxidised in synthetic air $\left(20.5 \% \quad \mathrm{O}_{2}\right.$ and $79.5 \% \mathrm{~N}_{2}$ ) at $700{ }^{\circ} \mathrm{C}$ up to $1000 \mathrm{~h}$ with continuous recording of the mass gain.

Microstructures before and after oxidation tests were studied using scanning electron microscopes (SEM) JEOL JSM $7500 \mathrm{~F}$ with cold field emission gun (at acceleration voltage $2 \mathrm{kV}$ ) and JEOL JSM-5510 LV (at acceleration voltage $20 \mathrm{kV}$ ) equipped with an energy-dispersive X-ray spectrometer (EDS) IXRF500. Phase identification was performed by X-ray diffraction (XRD) using a Siemens D500 diffractometer with $\mathrm{Cr} K_{\alpha}$ and $\mathrm{Cu} K_{\alpha}$ cathodes. Surface chemical analysis was carried out by X-ray photoelectron spectroscopy (XPS) on an Omicron Nanotechnology ESCA Probe P. Before XPS analysis, the surface layer of $\approx 30 \mathrm{~nm}$ thickness was etched by an ion gun (Ar ions, $5 \mathrm{kV}$ ) to avoid adventitious hydrocarbons adsorbed from the atmosphere.

\section{Results and discussion}

The microstructures of both SPS SP and DP specimens were homogeneous with only very low amounts of fine pores and remnants of fine oxides on particle boundaries [24]. For all the plasma sprayed coatings the typical microstructure consisted of flattened splats created from fully molten powders and partially unmolten particles. Oxides, pores and cracks were present in the coating (Fig. 1). EDS revealed localized depletion of Al. Mean Al depletion was 5 at.\% and 4 at.\% in the case of SP and DP coatings, respectively.

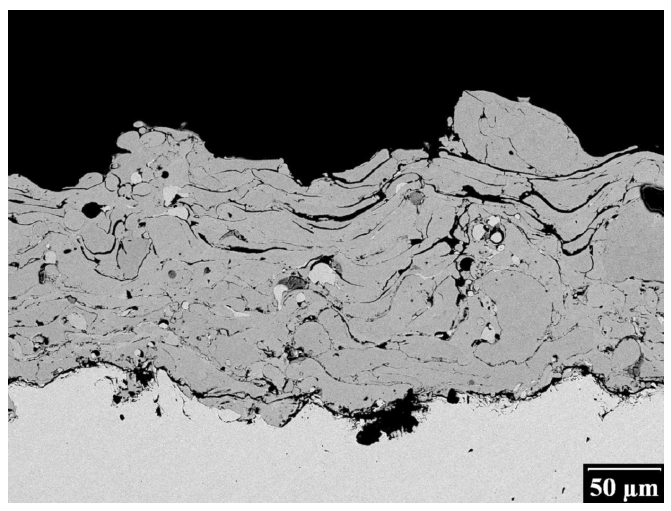

Fig. 1. Microstructure of the plasma sprayed coating (GSP SP).

The kinetics of oxidation measured by thermogravimetry at $700{ }^{\circ} \mathrm{C}$ is illustrated in Fig. 2 by showing the specific mass gain vs. time in a parabolic scale. Since diffu- sion processes in the oxide scale are rate determining for the oxidation, the kinetics can generally be described by the parabolic rate law of diffusion controlled oxidation, even if the measured kinetics in wide temperature ranges do not closely correspond to this law

$$
\frac{\Delta m}{S}=\sqrt{k_{\mathrm{p}} t},
$$

where $\Delta m$ is the mass gain, $S$ is the sample surface, $k_{\mathrm{p}}$ is the parabolic rate constant, $t$ is the time.

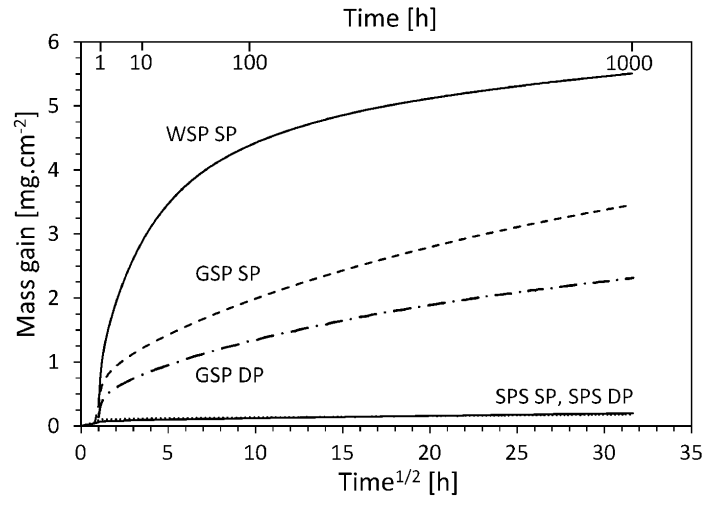

Fig. 2. The kinetics of oxidation measured by thermogravimetry at $700^{\circ} \mathrm{C}$.

All samples show a continuous decrease in the slope of the parabolic plot up to the end of the test. The data clearly indicate different oxidation kinetics for the SPS and plasma sprayed samples. The specific mass gain was considerably higher in the case of plasma sprayed samples and the steady-state parabolic rate constants were two orders of magnitude higher than in the case of SPS samples (Table). No drops due to spallation of the formed scales can be noticed on the measured thermogravimetric curves for any of the investigated samples.

TABLE

Parabolic rate constants (estimated from record between 400 and $1000 \mathrm{~h}$ ) and the oxide type after the oxidation test (XRD).

\begin{tabular}{c|c|c}
\hline \hline Sample & $k_{\mathrm{p}}\left[\mathrm{g}^{2} \mathrm{~cm}^{-4} \mathrm{~s}^{-1}\right]$ & Oxide type \\
\hline SPS SP & $3.21 \times 10^{-15}$ & $\mathrm{Al}_{2} \mathrm{O}_{3}$ \\
SPS DP & $1.23 \times 10^{-15}$ & $\mathrm{Al}_{2} \mathrm{O}_{3}$ \\
GSP SP & $8.77 \times 10^{-13}$ & $\mathrm{Al}_{2} \mathrm{O}_{3}$ \\
GSP DP & $3.56 \times 10^{-13}$ & $\mathrm{Al}_{2} \mathrm{O}_{3}$ \\
WSP SP & $3.04 \times 10^{-13}$ & $\mathrm{Al}_{2} \mathrm{O}_{3}, \mathrm{Fe}_{2} \mathrm{O}_{3}$
\end{tabular}

FeAl alloys have been extensively studied at temperatures above $800^{\circ} \mathrm{C}$ e.g. Refs. [6, 19, 22, 26, 27]. Unfortunately, the occurrence of different polytypes of $\mathrm{Al}_{2} \mathrm{O}_{3}$ at higher temperatures or in different environments makes it difficult to extrapolate the results obtained at higher temperatures to the experiments performed in this work. The measured values of the parabolic rate constants $k_{\mathrm{p}}$ 
of our SPS materials are slightly higher than those obtained for an Fe-25Al-2Ta (at.\%) alloy studied under the same conditions $\left(700^{\circ} \mathrm{C}, 1000 \mathrm{~h}\right)$ [28]. As the present results once more reveal that the oxidation behaviour improves with increasing $\mathrm{Al}$ content, i.e. the parabolic rate constants $k_{\mathrm{p}}$ of the DP materials are always lower than those of the SP materials, the considerable smaller grain size of the present materials could be responsible that the parabolic rate constants $k_{\mathrm{p}}$ of these powder metallurgical processed materials are slightly higher than those obtained for the as-cast $\mathrm{Fe}-25 \mathrm{Al}-2 \mathrm{Ta}$ (at.\%) alloy.

After oxidation test, XPS analysis carried out on SPS SP, SPS DP, GSP DP and WSP SP samples revealed the presence of aluminium oxide (all samples) and iron oxide (plasma sprayed). Aluminium oxide was identified as $\mathrm{Al}_{2} \mathrm{O}_{3}$-type with $\mathrm{Al}$ line $2 p_{3 / 2}$ and binding energy $\approx 74.5 \mathrm{eV}$. The oxide layer was too thin for XRD in the Bragg-Brentano geometry except the WSP SP sample in which $\mathrm{Fe}_{2} \mathrm{O}_{3}$ (hematite) was found. In other samples, grazing incidence (at angle of $3^{\circ}$ ) geometry revealed $\gamma-\mathrm{Al}_{2} \mathrm{O}_{3}$ (Fig. 3).

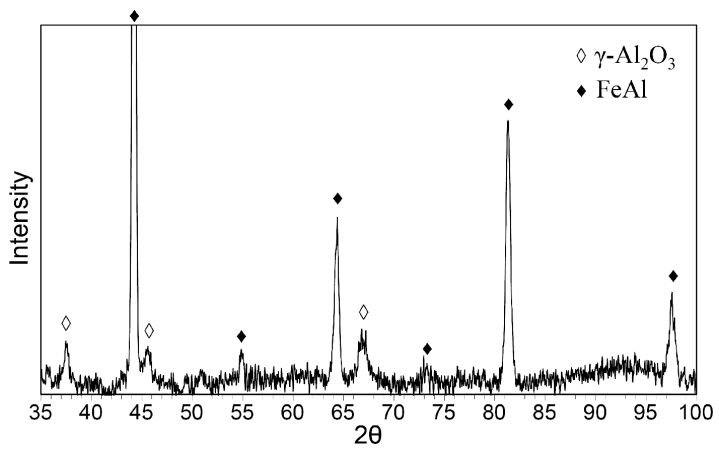

Fig. 3. XRD phase identification after the oxidation test (GSP SP).

SEM observation of oxidized SPS SP and DP samples confirmed a compact oxide scale after the tests (no spallation or cracking of the oxide scale). The morphology of the oxide scale can be seen in Fig. 4. For the plasma sprayed samples (GSP, WSP), a similar morphology of the alumina oxide scale is observed on the splats surface (Fig. 4b) but the particles are coarser compared to the SPS bulk samples surface (Fig. 4a). Besides $\mathrm{Al}_{2} \mathrm{O}_{3}$, the $\mathrm{Fe}_{2} \mathrm{O}_{3}$ oxides in form of nodules were identified by EDS in the plasma sprayed samples. These nodules were covered by whisker-like aluminium oxide fibres growing from underlying $\mathrm{Fe}_{2} \mathrm{O}_{3}$ (Fig. 4c). The highest density of $\mathrm{Fe}_{2} \mathrm{O}_{3}$ nodules with whisker-like aluminium oxides was found in the WSP SP sample. Also, the WSP SP coatings exhibited the highest oxidation kinetics in the initial stage and then slightly lower than kinetics observed for GSP SP and GSP DP (for $t>200 \mathrm{~h}$ ). This is most likely due to the fact that even if aluminium has a thermodynamically higher tendency to form $\mathrm{Al}_{2} \mathrm{O}_{3}$ than iron does have to form $\mathrm{Fe}_{2} \mathrm{O}_{3}$, the latter grows faster causing a rapid mass gain. When the protective $\mathrm{Al}_{2} \mathrm{O}_{3}$ scale is
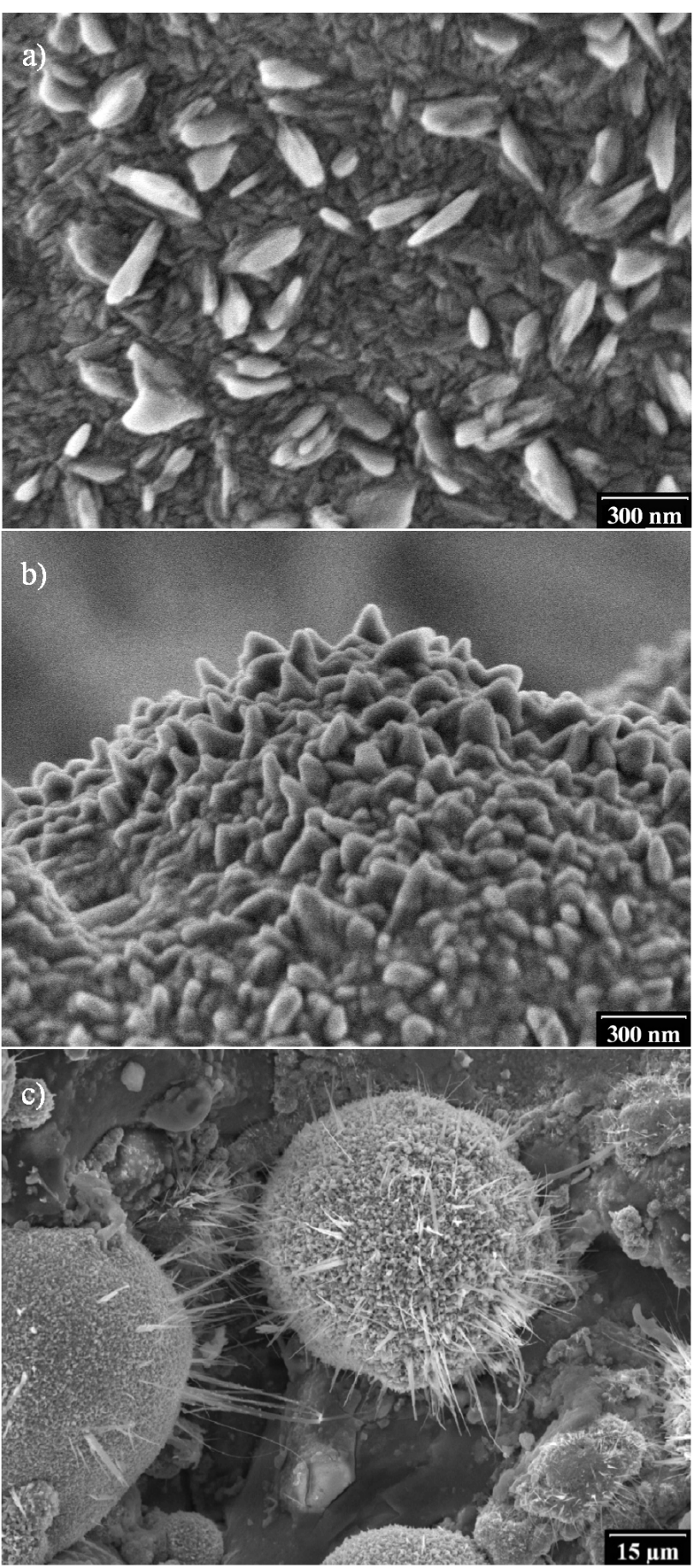

Fig. 4. Oxide scale morphology after $1000 \mathrm{~h}$ oxidation at $700{ }^{\circ} \mathrm{C}$ : (a) SPS SP, (b) GSP SP, (c) WSP SP.

formed beneath the $\mathrm{Fe}_{2} \mathrm{O}_{3}$ oxide, the coatings regain a good oxidation resistance as shown by a decrease of $k_{\mathrm{p}}$.

\section{Conclusions}

The oxidation behaviour of spark plasma sintered and plasma sprayed binary $\mathrm{Fe}-43 \mathrm{at} . \% \mathrm{Al}$ and $\mathrm{Fe}-56 \mathrm{at} . \% \mathrm{Al}$ 
powders was characterized in synthetic air at $700{ }^{\circ} \mathrm{C}$. The results can be summarized as follows:

1. The SPS samples formed compact, well-adherent $\mathrm{Al}_{2} \mathrm{O}_{3}$ scales which show slow oxidation kinetics. No spallation, cracking or cavity formation was observed.

2. The oxidation kinetics of the plasma sprayed samples is significantly faster than that of the SPS samples due to a higher roughness of the plasma sprayed samples and a heterogeneous composition of the coatings.

3. Uneven $\mathrm{Al}$ depletion in the plasma sprayed coatings can lead to local changes from protective $\mathrm{Al}_{2} \mathrm{O}_{3}$ scale to $\mathrm{Fe}_{2} \mathrm{O}_{3}$ formation if the local $\mathrm{Al}$ content is lower than critical for alumina formation. A good control of the spray parameters is therefore an essential step towards oxidation resistant iron aluminide coatings.

\section{Acknowledgments}

This research has been supported by the Czech Technical University in Prague SGS grant 10/300/OHK4/ $3 \mathrm{~T} / 14$.

\section{References}

[1] W.C. Hagel, Corrosion 21, 316 (1965).

[2] B. Schmidt, P. Nagpal, I. Baker, in: High- Temperature Ordered Intermetallic Alloys III, MRS Symp. Proc., Vol. 133, Eds. C.T. Liu, A.I. Taub, N.S. Stoloff, C.C. Koch, Materials Research Society, PA 1989, p. 755.

[3] J.R. Stephens, in: High-Temperature Intermetallic Ordered Alloys, MRS Symp. Proc., Vol. 39, Eds. C.C. Koch, C.T. Liu, N.S. Stoloff, Materials Research Society, PA 1985, p. 381.

[4] P.F. Tortorelli, K. Natesan, Mater. Sci. Eng. A 258, 115 (1998).

[5] R. Prescott, M.J. Graham, Oxid. Met. 38, 73 (1992).

[6] I. Rommerskirchen, B. Eltester, H.-J. Grabke, Mater. Corros. 47, 646 (1996).

[7] M. Sakiyama, P. Tomaszewicz, G.R. Wallwork, Oxid. Met. 13, 311 (1979).
[8] J.H. Schneibel, in: Processing, Properties, and Applications of Iron Aluminides, Eds. J.H. Schneibel, M.A. Crimp, TMS, Warrendale, PA, 1994, p. 329.

[9] I. Baker, P.R. Munroe, Int. Mater. Rev. 42, 181 (1997).

[10] P. Haušild, J. Siegl, P. Málek, V. Š́ma, Intermetallics 17, 680 (2009).

[11] N.S. Stoloff, Mater. Sci. Eng. A 258, 1 (1998).

[12] D.G. Morris, S. Gunter, Mater. Sci. Eng. A 208, 7 (1996).

[13] Y. Minamino, Y. Koizumi, N. Tsuji, N. Hirohata, K. Mizuuchi, Y. Ohkanda, Sci. Technol. Adv. Mater. 5, 133 (2004).

[14] S. Paris, E. Gaffet, F. Bernard, Z.A. Munir, Scr Mater. 50, 691 (2004).

[15] G. Ji, T. Grosdidier, N. Bozzolo, S. Launois, Intermetallics 15, 108 (2007).

[16] L. D'Angelo, L. D'Onofrio, G. Gonzalez, J. Alloys Comp. 483, 154 (2009).

[17] T. Grosdidier, G. Ji, F. Bernard, E. Gaffet, Z.A. Munir, S. Launois, Intermetallics 14, 1208 (2006).

[18] J.M. Guilemany, C.R.C Lima, N. Cinca, J.R. Miguel, Surf. Coat. Technol. 201, 2072 (2006).

[19] J.M. Guilemany, N. Cinca, S. Dosta, C.R.C Lima, Intermetallics 15, 1384 (2007).

[20] T. Grosdidier, H.L. Liao, A. Tidu, in: Thermal Spray: Surface Engineering via Applied Research, Ed. C.C. Berndt, ASM International, Materials Park, OH 2000, p. 1341.

[21] C. Xiao, W. Chen, Surf. Coat. Technol. 201, 3625 (2006).

[22] N. Masahashi, S. Watanabe, S. Hanada, ISIJ Int. 41, 1010 (2001).

[23] J. Xiang, X. Zhu, G. Chen, Z. Duan, Y. Lin, Y. Liu, Trans. Nonferrous Met. Soc. China 19, 1545 (2009).

[24] T. Skiba, P. Haušild, M. Karlík, K. Vanmeensel, J. Vleugels, Intermetallics 18, 1410 (2010).

[25] R. Mušálek, O. Kovářík, T. Skiba, P. Haušild, M. Karlík, J. Colmenares-Angulo, Intermetallics 18, 1415 (2010).

[26] M. Palm, G. Sauthoff, Intermetallics 12, 1345 (2004).

[27] P. Novák, M. Zelinková, J. Šerák, A. Michalcová, M. Novák, D. Vojtěch, Intermetallics 19, 1306 (2011).

[28] A. Hotař, M. Palm, Intermetallics 18, 1390 (2010). 